\title{
Crystalline phase characterization of glass-ceramic glazes
}

\author{
M.G. Rasteiro ${ }^{\text {a,*, }}$, Tiago Gassman ${ }^{\text {b }}$, R. Santos ${ }^{\text {c }}$, E. Antunes ${ }^{a}$ \\ ${ }^{\text {a } C h e m i c a l ~ E n g i n e e r i n g ~ D e p a r t m e n t, ~ C o i m b r a ~ U n i v e r s i t y, ~ P o ́ l o ~ I I, ~}$ \\ Pinhal de Marrocos, 3030-290 Coimbra, Portugal \\ ${ }^{\mathrm{b}}$ Colorobbia Portugal, Anadia, Portugal \\ ${ }^{\mathrm{c}}$ Centro Tecnológico da Cerâmica e do Vidro, Coimbra, Portugal
}

Received 6 May 2005; received in revised form 2 September 2005; accepted 3 October 2005

Available online 18 January 2006

\begin{abstract}
The firing process of five raw crystalline frits was investigated by means of DTA, XRD, heating microscopy and dilatometry. The chemical composition of the frits was determined by FAAS, to define the main glass-ceramic system of each frit. The final crystalline structure detected for the sintered frits conformed to the temperatures for which transformations were obtained during heating. The existence of a relationship between the crystallization process and sintering behaviour was confirmed. During devitrification, the sintering process stops, confirming that crystalline formation affects the sintering behaviour of the frits. In this case, the thermal properties of the final product are not only dependent on oxide composition but also on the crystalline phases. It was established that the addition of adequate compounds could induce the formation of crystalline phases on some glass-ceramic frits.
\end{abstract}

(C) 2005 Elsevier Ltd and Techna Group S.r.l. All rights reserved.

Keywords: A. Sintering; D. Glass-ceramics; D. Glass; Crystallization

\section{Introduction}

In recent years there have been changes in the properties of everyday ceramic products, because of the need of improving the resistance of ceramic tiles due to its use, for instance, on floors of large commercial areas. In these applications the traditional glaze has a too low abrasive resistance and loses its surface characteristics such as brightness, colour and superficial texture very easily [1]. Thus, it became necessary to develop new products to satisfy the requirements of the ceramic tile industry and the demand of coatings with specific properties. These features can be achieved using suitable glass-ceramic compositions [2]. Glass-ceramic materials are polycrystalline solids with a residual glassy matrix leading to a polycrystalline microstructure that allows achievement of a better performance to abrasiveness and an increased resistance compared to traditional glasses [2]. This microstructure can be obtained by a sintering process where crystallization and densification of glass particles occurs during firing.

\footnotetext{
* Corresponding author. Fax: +351 239798703.

E-mail address: mgr@eq.uc.pt (M.G. Rasteiro).
}

Glazes are commonly applied on surfaces as aqueous suspensions of frits and other additives, also called enamels [2]. Frits are particles of pre-melted glass and, in the case of glassceramic glazes these frits show a glass-ceramic system. However, it is necessary to control the crystallisation process to obtain a product with appropriate technical properties and adequate aesthetics [3]. In fact, it has been shown that to get a well-crystallized product with minimum porosity, glass particles must densify before crystallization starts. Therefore, it is necessary to choose an adequate frit composition for the glass-ceramic to sinter in the right moment and to devitrify the desired percentage of crystals. Moreover, it is necessary to keep a sufficient open porosity to allow the escape of the reaction gases formed during firing [2,3]. The final formulation of the enamel depends also on several other factors such as a proper maturation time, required thermal expansion coefficient and on the reactivity with the ceramic support. Indeed, to apply the enamel as a coating, on ceramic body surfaces, it must have a thermal expansion coefficient close to the thermal expansion coefficient of the body (in most cases around $70 \times 10^{-7}{ }^{\circ} \mathrm{C}^{-1}$ ) to avoid strains on the tile [4].

What has been said shows that to formulate new glazes from glass-ceramic systems is a complex process since a lot of factors must be considered simultaneously. Thus, to guarantee 
Table 1

Chemical composition of the frits (wt.\%)

\begin{tabular}{|c|c|c|c|c|c|c|c|c|c|c|c|c|c|}
\hline Sample & $\mathrm{SiO}_{2}$ & $\mathrm{Al}_{2} \mathrm{O}_{3}$ & $\mathrm{Fe}_{2} \mathrm{O}_{3}$ & $\mathrm{Na}_{2} \mathrm{O}$ & $\mathrm{Li}_{2} \mathrm{O}$ & $\mathrm{B}_{2} \mathrm{O}_{3}$ & $\mathrm{~K}_{2} \mathrm{O}$ & $\mathrm{CaO}$ & $\mathrm{MgO}$ & $\mathrm{PbO}$ & $\mathrm{ZnO}$ & $\mathrm{BaO}$ & $\mathrm{ZrO}_{2}$ \\
\hline A & 46.00 & 21.00 & 0.11 & 0.48 & 0.00 & 0.00 & 0.73 & 20.00 & 9.10 & 0.06 & 0.29 & 0.72 & 0.57 \\
\hline B & 45.00 & 31.00 & 0.11 & 0.44 & 1.60 & 0.00 & 1.40 & 1.50 & 16.00 & 0.91 & 0.30 & 0.13 & 1.20 \\
\hline $\mathrm{C}$ & 39.00 & 14.00 & 0.03 & 0.54 & 1.20 & 0.00 & 0.49 & 0.62 & 0.04 & 0.11 & 1.70 & 38.00 & 2.40 \\
\hline $\mathrm{D}$ & 56.00 & 15.00 & 0.18 & 0.40 & 0.00 & 0.00 & 1.10 & 21.00 & 0.57 & 1.20 & 0.11 & 0.04 & 2.20 \\
\hline $\mathrm{E}$ & 41.00 & 27.00 & 0.10 & 19.00 & 0.16 & 1.80 & 0.23 & 0.91 & 0.12 & 0.36 & 0.11 & 0.18 & 7.00 \\
\hline
\end{tabular}

that the required product is obtained, a systematic research must be performed at lab scale. The first part of this work was aimed at the physical and chemical characterization of some commercial glass-ceramic frits. The combination of several techniques allowed the understanding and description of the behaviour of glass-ceramic frits during firing. In the second part of the work the influence of some additives on glaze properties was studied for two of the commercial glass-ceramic frits characterized previously. Furthermore, the behaviour of the new glass-ceramic frits studied was compared with the behaviour of traditional frits with similar composition (same oxides).

\section{Experimental methodology}

Five commercial glass-ceramic frits (named A to E) with different composition were studied, as shown in Table 1. After drying at $100{ }^{\circ} \mathrm{C}$, the glass was ground in a ball mill with water (approximately $40 \%$, w/w), during $55 \mathrm{~min}$, to obtain a residue less than $2 \%$ in the 325 mesh sieve. The residue was measured in a Bayer measuring sieve and the density of the aqueous suspension was determined using a pycnometer. After drying the suspension at $100{ }^{\circ} \mathrm{C}$ a fine powder was obtained and sequently characterized according to the following techniques.

The chemical composition of frits was determined using Flame Atomic Absorption Spectroscopy-FAAS and gravimetric analysis. The characteristic glass transition temperature $\left(T_{\mathrm{g}}\right)$ and the crystallization temperature $\left(T_{\mathrm{c}}\right)$ were determined by differential thermal analysis (DTA; heating rate of $10^{\circ} \mathrm{C} /$ min in air). The heat treatment was carried out in an alumina crucible and using $\mathrm{Al}_{2} \mathrm{O}_{3}$ as the reference material.

Crystalline phases formed during firing were detected and identified by X-ray diffraction (XRD). Samples were prepared

Table 2

Maximum firing temperatures for XRD sample preparation

\begin{tabular}{llrrr}
\hline Samples & \multicolumn{4}{l}{ Maximum firing temperatures $\left({ }^{\circ} \mathrm{C}\right)$} \\
\hline A & 0 & 800 & 920 & 1050 \\
B & 0 & 850 & 940 & 1100 \\
C & 0 & 790 & 810 & 860 \\
D & 0 & 840 & 1000 & 1200 \\
E & 0 & 700 & 750 & 800 \\
M & 0 & 690 & 1100 & - \\
N & 0 & 750 & 900 & 1100 \\
\hline
\end{tabular}

by firing quenched glass-ceramics powders at several temperatures. The temperatures selected (Table 2) corresponded to temperatures just before and after the exothermic peak of crystallization detected by DTA. This way, it was possible to characterize, by XRD, the devitrification behaviour of the frits. The raw material was also investigated by XRD to confirm the non-crystalline structure of the initial frits. Before sintering the samples in a laboratory furnace, with a heating rate of $10^{\circ} \mathrm{C} /$ min, the powders were pressed in a steel mould of rectangular section $(50 \mathrm{~mm} \times 5 \mathrm{~mm} \times 5 \mathrm{~mm})$. The sintered samples were ground in a ring mill and sieved through a $75 \mu \mathrm{m}$ sieve. The $\mathrm{X}$ ray diffractometer was operated using a $2 \theta$ range from $0^{\circ}$ to $60^{\circ}$ at a scanning speed of $1 \% \mathrm{~min}$.

In addition, the sintering behaviour was characterized by heating microscopy. The glass-ceramics powders were pressed in a cubic mould $(3 \mathrm{~mm} \times 3 \mathrm{~mm} \times 3 \mathrm{~mm})$ and heated from room temperature to $1400{ }^{\circ} \mathrm{C}$ at a heating rate of $10^{\circ} \mathrm{C} / \mathrm{min}$. The change of shape of the probe, during heating was registered by a camera and the characteristic points were determined on the basis of modifications of the shape of the probe leading to changes on the height and on the contact angle with the sample holder. The characteristic temperatures were:

- sintering point $(S)$ : the temperature corresponding to $5 \%$ contraction of the sample initial height;

- softening point $(M)$ : temperature for which round edges were visible;

- ball point $(B)$ : temperature for which the probe appeared like a sphere;

- half ball point (HB): temperature for which the height is half of the base;

- flow point $(F)$ : temperature for which the sample is melted down to $1 / 3$ of its initial height.

The record also allowed obtaining the sintering curve (height of sample versus temperature).

The thermal properties of the final products (thermal expansion coefficient, $\alpha$, transformation point, $T_{\mathrm{d}}$ and dilatometric softening point, $T_{\mathrm{s}}$ ) were measured in a dilatometer using a heating rate of $10{ }^{\circ} \mathrm{C} / \mathrm{min}$. The powder was previously pressed, in the same way as for the XRD analysis. For these tests, the glass-ceramic powder tablet was fired until ball point using a heating rate of $10^{\circ} \mathrm{C} / \mathrm{min}$, followed by a cooling cycle with the same rate $\left(10^{\circ} \mathrm{C} / \mathrm{min}\right)$. 
Table 3

Chemical composition of the additivated samples (wt.\%)

\begin{tabular}{|c|c|c|c|c|c|c|c|c|c|c|c|c|c|}
\hline Sample & $\mathrm{SiO}_{2}$ & $\mathrm{Al}_{2} \mathrm{O}_{3}$ & $\mathrm{Fe}_{2} \mathrm{O}_{3}$ & $\mathrm{Na}_{2} \mathrm{O}$ & $\mathrm{Li}_{2} \mathrm{O}$ & $\mathrm{B}_{2} \mathrm{O}_{3}$ & $\mathrm{~K}_{2} \mathrm{O}$ & $\mathrm{CaO}$ & $\mathrm{MgO}$ & $\mathrm{PbO}$ & $\mathrm{ZnO}$ & $\mathrm{BaO}$ & $\mathrm{ZrO}_{2}$ \\
\hline M & 46.00 & 21.00 & 0.11 & 0.48 & 0.00 & 0.00 & 0.73 & 20.00 & 9.10 & 0.06 & 0.29 & 0.72 & 0.57 \\
\hline $\mathrm{N}$ & 51.22 & 21.71 & 0.04 & 0.16 & 2.05 & 0.00 & 0.60 & 2.45 & 7.34 & 0.34 & 0.11 & 0.05 & 8.85 \\
\hline
\end{tabular}

\section{Results and discussion}

\subsection{Chemical characterization}

The chemical composition of the frits studied in this work has been shown previously in Table 1. Additionally, two frits with additives were also studied: sample $\mathrm{M}$, made of frit $\mathrm{D}$ with $5 \%$ of alumina and sample $\mathrm{N}$, a composed enamel containing $37 \%$ of frit B. Their chemical composition is shown in Table 3.

Regarding the composition of frits $\mathrm{A}$ to $\mathrm{E}$, they have the same elements but in different concentrations, exception made for frits $\mathrm{B}$ and $\mathrm{C}$ that do also contain $\mathrm{Li}_{2} \mathrm{O}$ and for frit $\mathrm{E}$ that contains both $\mathrm{B}_{2} \mathrm{O}_{3}$ and $\mathrm{Li}_{2} \mathrm{O}$.

In the frits composition there are always predominant elements describing a glass-ceramic system. Except for frit A, that shows a quaternary system, all frits presented a ternary system. If we refer to the phase diagram of each glass-ceramic system [5] and using the chemical composition in Table 1, we may predict which is the crystalline phase that will devitrificate during the heat treatment. In Table 4, the glass-ceramic system

Table 4

Glass-ceramic systems and most probable crystalline phases

\begin{tabular}{lll}
\hline Frit & Glass-ceramic system & Crystalline phase \\
\hline A & CMAS $\left(\mathrm{CaO}-\mathrm{MgO}-\mathrm{Al}_{2} \mathrm{O}_{3}-\mathrm{SiO}_{2}\right)$ & Anorthite-Diopside \\
B & MAS $\left(\mathrm{MgO}-\mathrm{Al}_{2} \mathrm{O}_{3}-\mathrm{SiO}_{2}\right)$ & Cordierite-Indialite \\
$\mathrm{C}$ & $\mathrm{BAS}\left(\mathrm{BaO}-\mathrm{Al}_{2} \mathrm{O}_{3}-\mathrm{SiO}_{2}\right)$ & Celsian \\
D & $\mathrm{CAS}\left(\mathrm{CaO}-\mathrm{Al}_{2} \mathrm{O}_{3}-\mathrm{SiO}_{2}\right)$ & Anorthite \\
E & $\mathrm{NAS}\left(\mathrm{Na}_{2} \mathrm{O}-\mathrm{Al}_{2} \mathrm{O}_{3}-\mathrm{SiO}_{2}\right)$ & Nepheline \\
\hline
\end{tabular}

for each frit and the corresponding crystalline phase that will be, most probably, formed during firing, are shown.

\subsection{Thermal properties}

The DTA results are given in Figs. 1-5. Table 5 summarises the temperatures measured by DTA and heating microscopy. From these values, only one exothermic peak relating to the formation of crystalline phases is observed, exception made for frits B and D. In frit B there are two crystallization peaks (see Fig. 2) whereas in frit $D$ there is no peak (Fig. 4). Additionally, frit D is the only frit presenting a ball temperature $(B)$.

From the analysis of the results given above it is possible to establish a relationship between the sintering behaviour and the crystallization process, for each frit. Indeed, considering Table 5, one can see that the glass transition temperature $\left(T_{\mathrm{g}}\right)$ always occurs before the sintering temperature $(S)$ while the softening temperature $(M)$ always happens after the crystallization event. To better visualize this correlation, we plotted the characteristic temperatures given in Table 5 on the graphic of sample height versus firing temperature. Figs. 6-8 show some examples of this representation for frits A-C.

From these figures it is also evident that sinterization finishes when the crystallization process occurs. That is, during crystallization the characteristic sample shrinkage, due to the sintering process stops. On the other hand, softening occurs only once the crystallization process is finished. Therefore, these results prove that crystal formation interferes with the sintering process of a crystalline frit. For frit D it was not

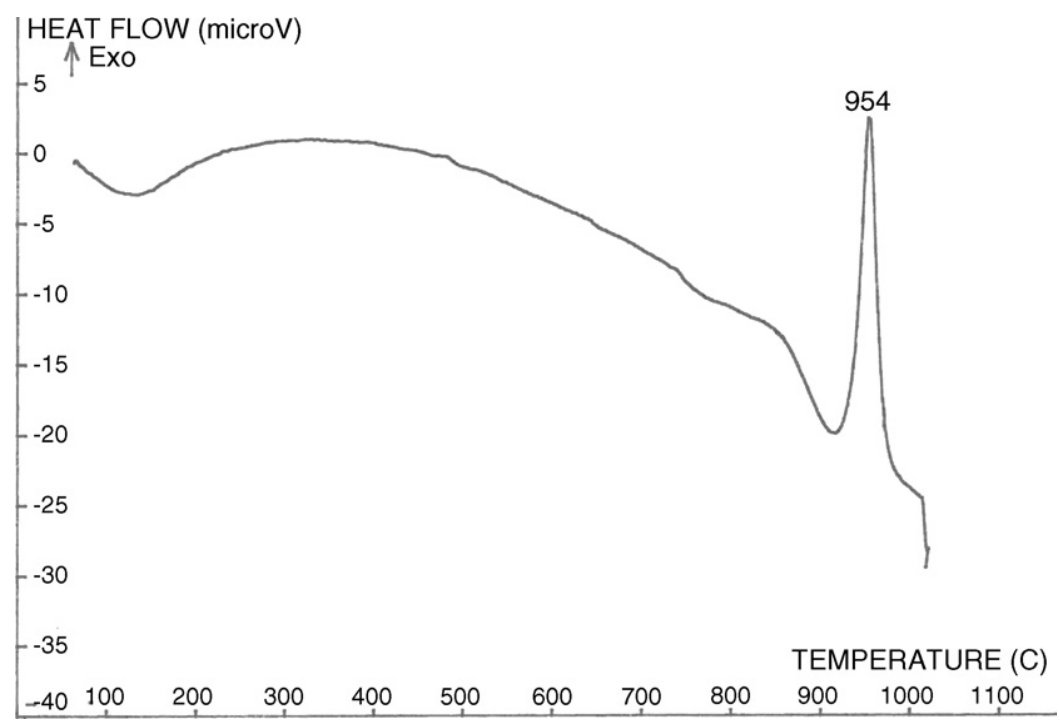

Fig. 1. DTA curve for frit A. 


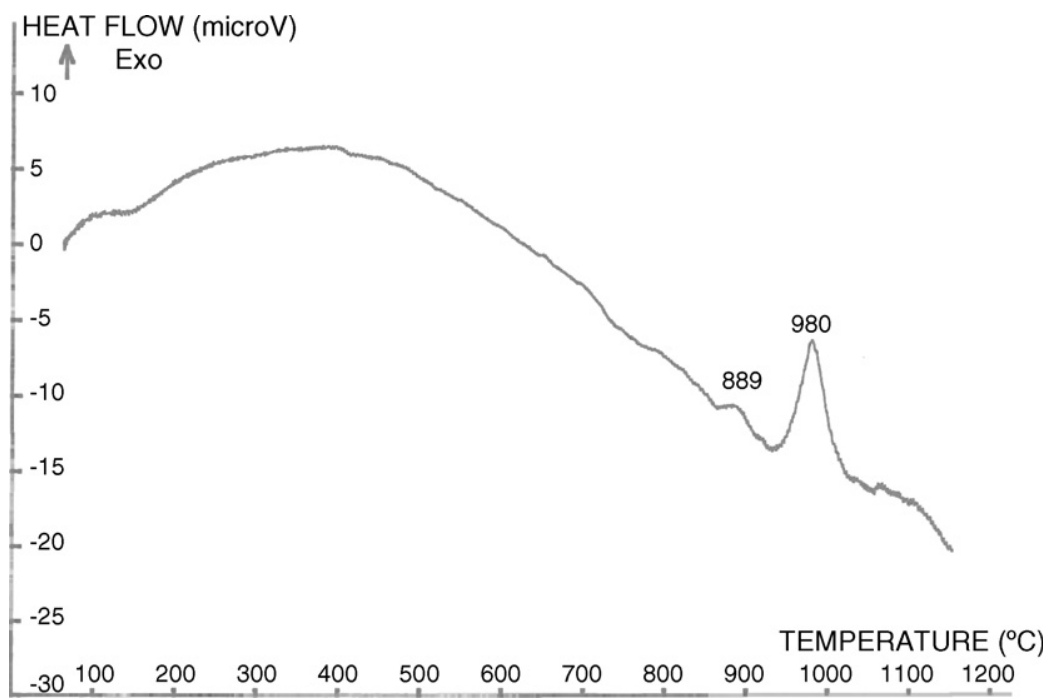

Fig. 2. DTA curve for frit B.

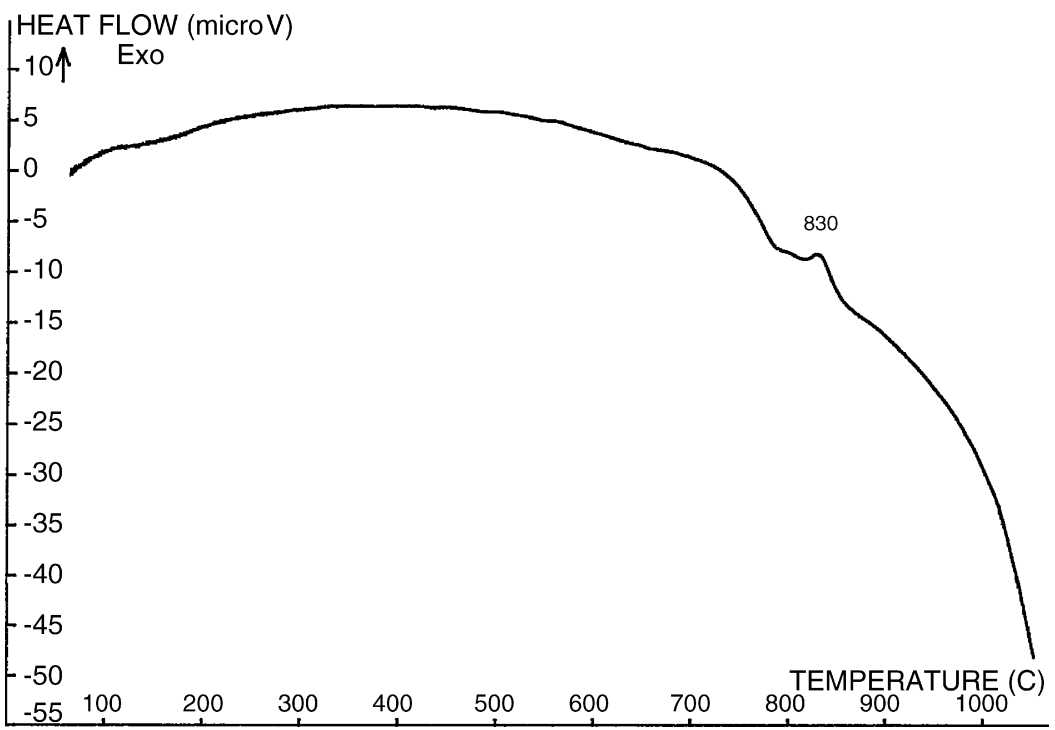

Fig. 3. DTA curve for frit C.

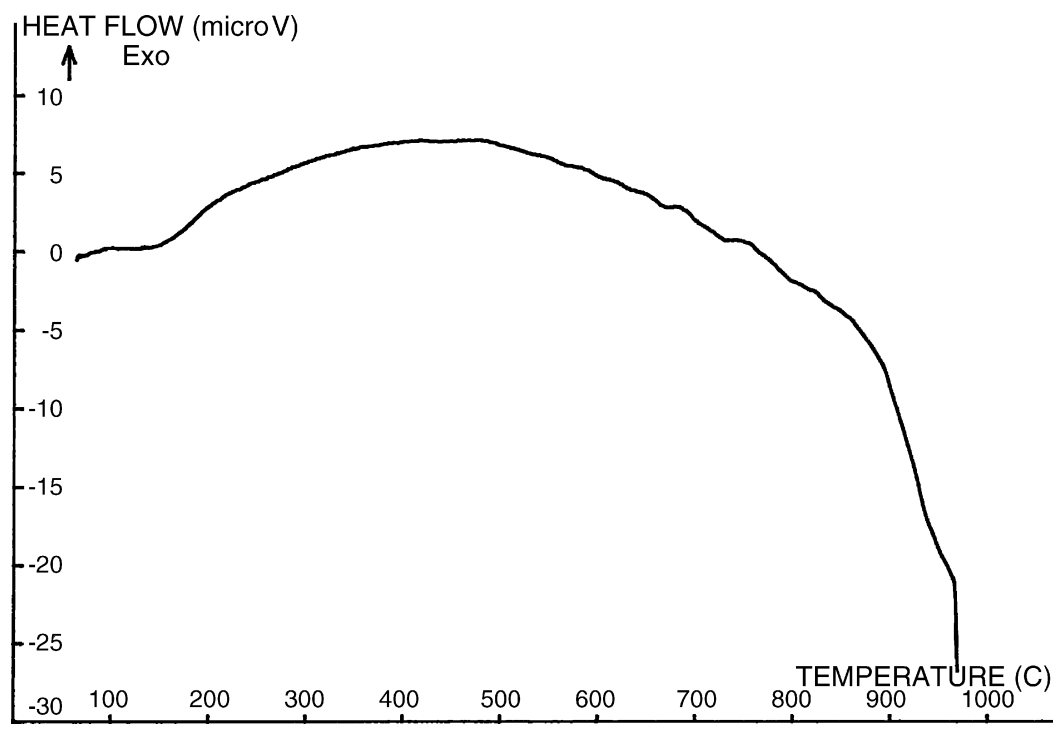

Fig. 4. DTA curve for frit D. 


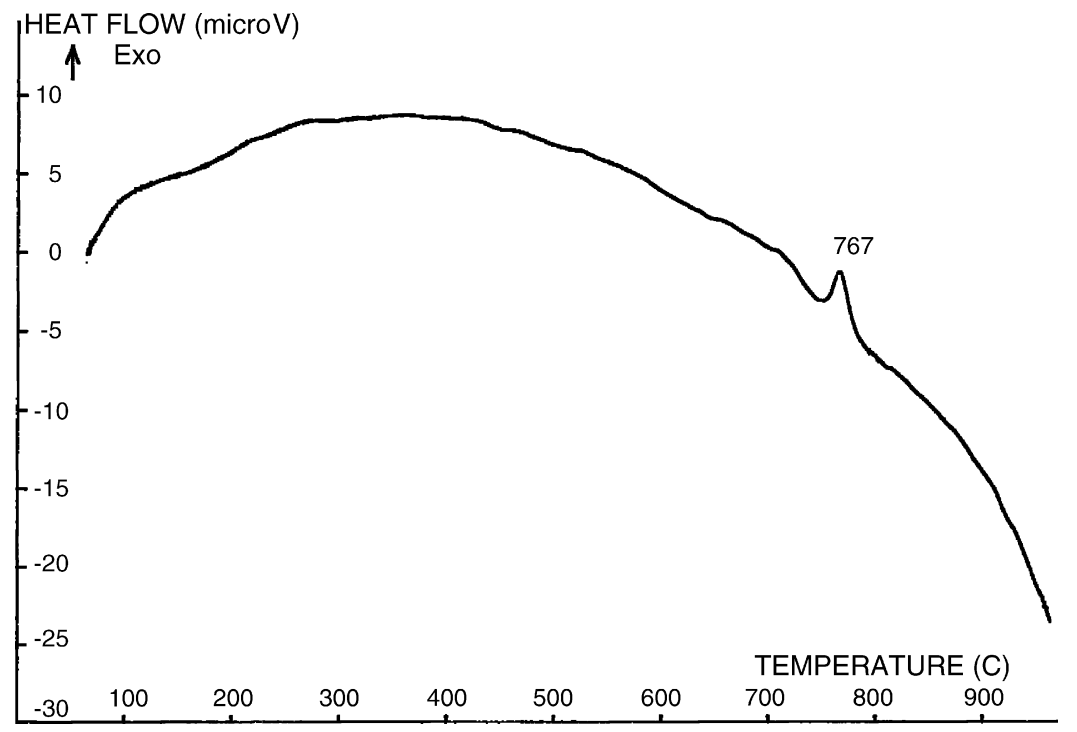

Fig. 5. DTA curve for frit E.

Table 5

Characteristic temperatures determined by DTA and heating microscopy

\begin{tabular}{|c|c|c|c|c|c|c|c|}
\hline \multirow[t]{2}{*}{ Sample } & \multicolumn{2}{|l|}{ DTA } & \multicolumn{5}{|c|}{ Heating microscopy } \\
\hline & $T_{\mathrm{g}}\left({ }^{\circ} \mathrm{C}\right)$ & $T_{\mathrm{c}}\left({ }^{\circ} \mathrm{C}\right)$ & $S\left({ }^{\circ} \mathrm{C}\right)$ & $M\left({ }^{\circ} \mathrm{C}\right)$ & $B\left({ }^{\circ} \mathrm{C}\right)$ & $\mathrm{HB}\left({ }^{\circ} \mathrm{C}\right)$ & $F\left({ }^{\circ} \mathrm{C}\right)$ \\
\hline A & 750 & 954 & 830 & 1247 & - & 1256 & 1300 \\
\hline B & 700 & $889 / 980$ & 850 & 1295 & - & 1314 & 1380 \\
\hline $\mathrm{C}$ & 750 & 830 & 750 & 1050 & - & 1291 & 1340 \\
\hline D & 780 & - & 890 & 955 & 1041 & 1188 & 1214 \\
\hline E & 710 & 767 & 680 & 1010 & - & 1280 & 1370 \\
\hline
\end{tabular}

Frit A

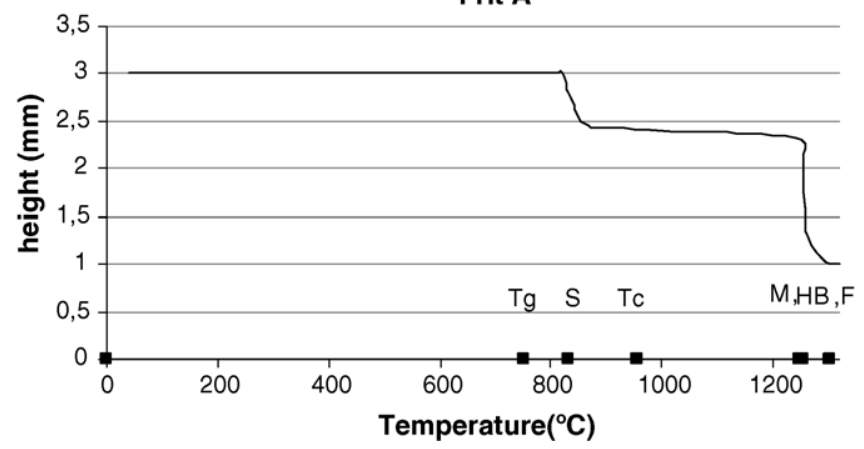

Fig. 6. Sample height and characteristic temperatures as a function of firing temperature for frit A.

\section{Frit B}

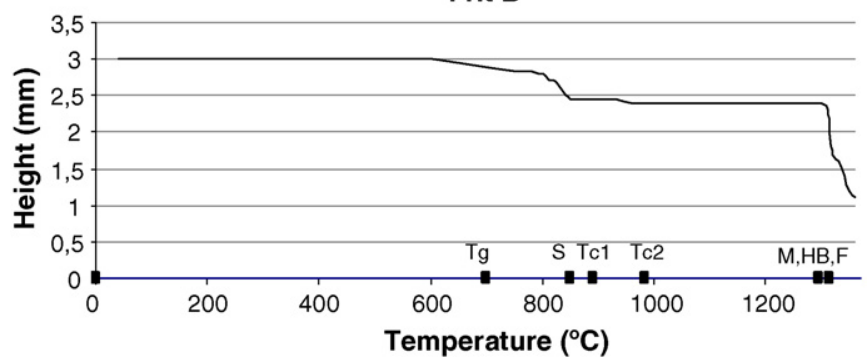

Fig. 7. Sample height and characteristic temperatures as a function of firing temperature for frit B. possible to establish this type of correlation. In fact, it was explained before that this frit did not exhibit an exothermic reaction, probably because there was no devitrification of a crystalline phase. That is the reason why, for frit $\mathrm{D}$, the softening temperature and the other temperatures measured by heating microscopy occurred earlier, the sintering behaviour showing the existence of a ball temperature.

\subsection{Crystalline structure}

The glassy systems investigated presented a crystalline phase after the thermal treatment, exception made for frit $\mathrm{D}$.

Frit C

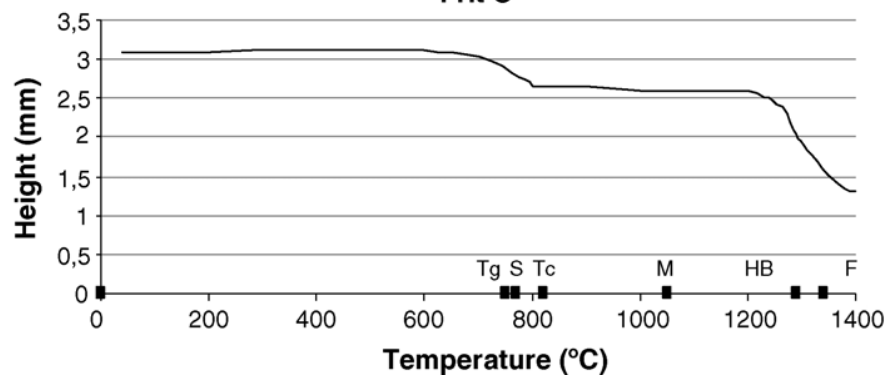

Fig. 8. Sample height and characteristic temperatures as a function of firing temperature for frit $\mathrm{C}$. 


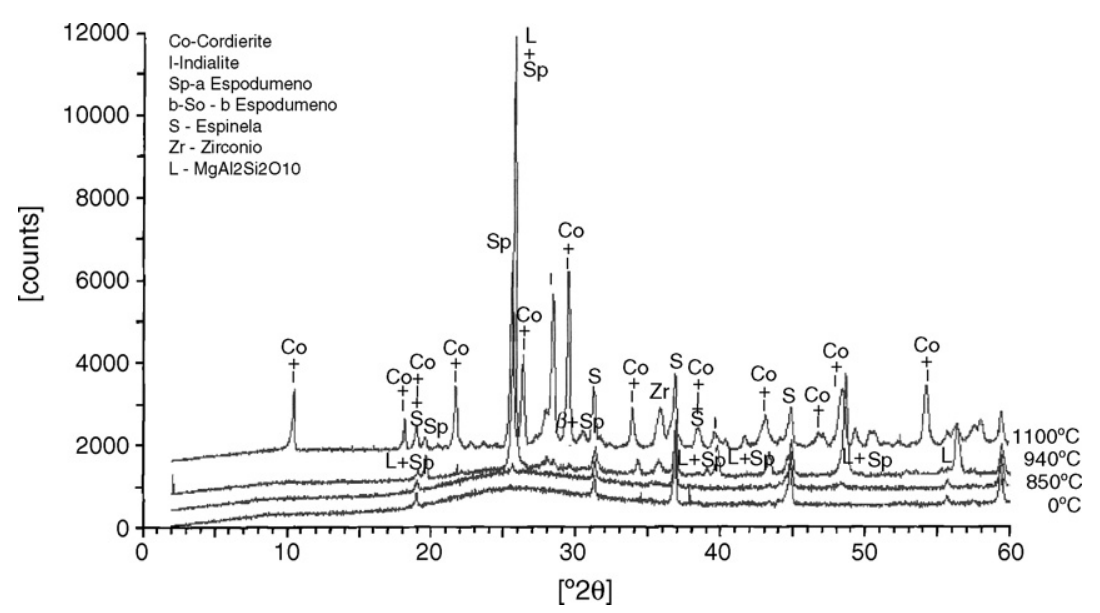

Fig. 9. X-ray diffraction patterns of the sintered frit B.

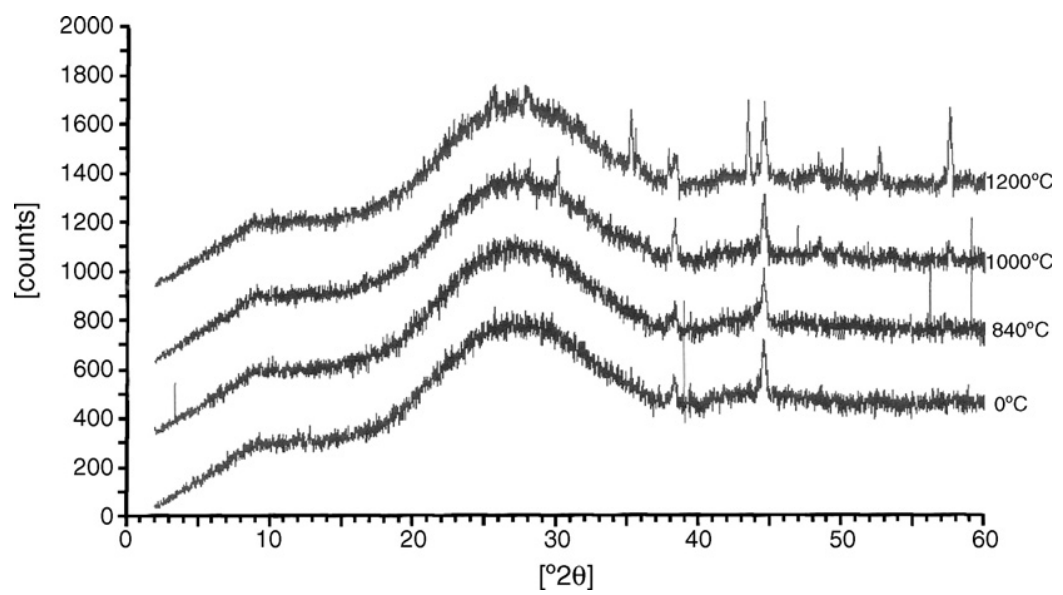

Fig. 10. X-ray patterns of the sintered frit D.

Figs. 9 and 10 show the XRD patterns, after sintering, for frits B and $\mathrm{D}$, respectively. We can see there the amorphous structure of the raw frit $\mathrm{D}\left(0^{\circ} \mathrm{C}\right)$. In the case of the raw frit $\mathrm{B}$, as well as for raw frits $\mathrm{C}$ and $\mathrm{E}$ (patterns not shown here), a crystalline structure already existed in the raw frit. The peaks at 38,5 and $44,8^{\circ} 2 \theta$ refer to the aluminium in the sample support.

In the case of frit $\mathrm{A}$, the results have shown that it remains amorphous until $800{ }^{\circ} \mathrm{C}$ and only after that it starts to form anorthite and diopside. At $920^{\circ} \mathrm{C}$, the sample exhibits a high amount of crystalline phase but, at $1050{ }^{\circ} \mathrm{C}$, it is possible to notice a small decrease of the anorthite peak intensity, benefiting the growth of diopside. The final product also contains residual gehlenite.

The final product $\mathrm{X}$-ray patterns for frit $\mathrm{B}$ are given in Fig. 11. It has been shown previously, in Fig. 9, that the raw sample contains spinel. Between 850 and $940{ }^{\circ} \mathrm{C}$ (first exothermic peak), the frit devitrificates leading to the formation of spodumene and a magnesium aluminosilicate $\left(\mathrm{MgAl}_{2}\right.$ $\mathrm{Si}_{3} \mathrm{O}_{10}$ ). For this temperature, cordierite also crystallizes though in a very small amount. During the second crystallization peak, XRD continues to detect spodumene indicating, however, the additional production of cordierite and indialite which are, now, the main crystalline phases. Therefore,
$\mathrm{MgAl}_{2} \mathrm{Si}_{3} \mathrm{O}_{10}$, formed during the first peak, was converted to form cordierite and indialite.

The XRD results for frit $\mathrm{C}$ show that the raw material contains vestigial celsian and baric orthoclase $(\mathrm{K}, \mathrm{Ba})(\mathrm{Si}, \mathrm{Al})_{4} \mathrm{O}_{8}$. Celsian continues to form during the exothermic event $\left(810-860{ }^{\circ} \mathrm{C}\right)$ becoming the principal crystalline structure. Banalsite formation is also detected during the exothermic peak.

The X-ray patterns of frit $\mathrm{D}$ for the different temperatures (see Fig. 10) are very similar. In fact, the raw material is strictly amorphous until $840^{\circ} \mathrm{C}$. After that, the sample crystallizes only vestiges of anorthite and diopside exhibiting no significant alterations, with temperature. This information agrees with the DTA results where no exothermic reaction was identified. Indeed, if we report to the CAS phase diagram, we can notice that the mixture equilibrium point is on the limit of the anorthite formation area. Thus, it is expected that only if alumina is added to the system it will be possible to move the mixture point into the area of anorthite formation, leading then to a higher degree of anorthite crystallization. Therefore, only in this condition it will be possible to say that frit $\mathrm{D}$ behaves as a glass-ceramic frit, as will be discussed later.

In the case of raw frit $\mathrm{E}$ it has been detected that it possesses, in its structure, vestigial amounts of sodium aluminosilicate 


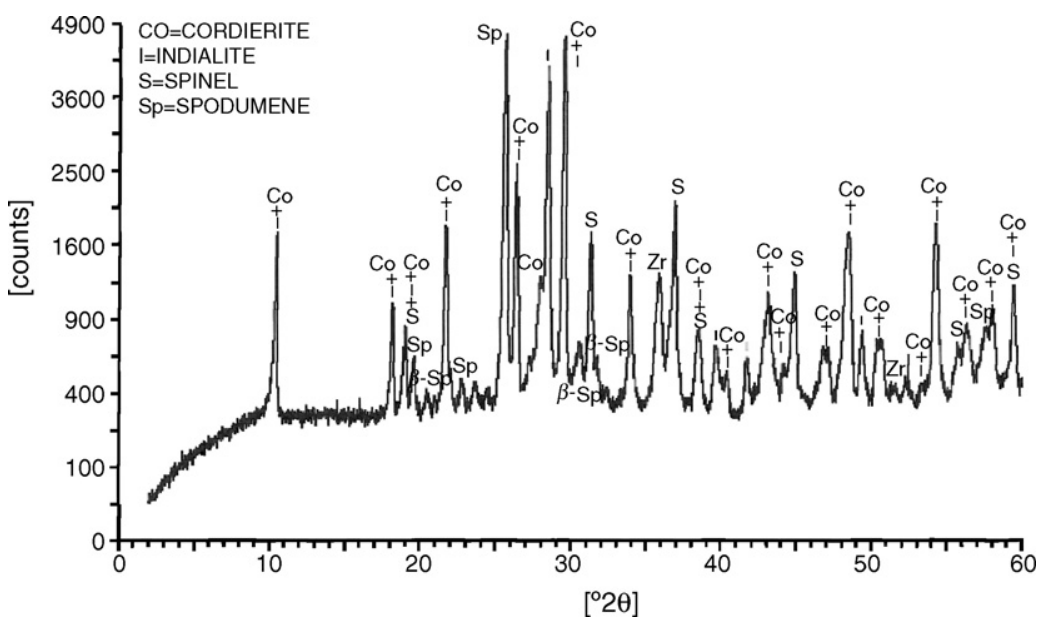

Fig. 11. X-ray pattern of sintered frit B at $1100{ }^{\circ} \mathrm{C}$.

$\left(\mathrm{NaAlSiO}_{4}\right)$. The formation of this mineral continues until the exothermic peak, being converted, after that, to hexagonal nepheline. Thus, at $750{ }^{\circ} \mathrm{C}$, it is detected by XRD a small amount of sodium aluminosilicate and nepheline, while at $800{ }^{\circ} \mathrm{C}$, only hexagonal nepheline is identified.

Generally speaking, it is possible to state that the main crystalline phases detected by XRD correspond to the crystalline phases foreseen by the ternary phase diagrams.

\subsection{Dilatometry results}

Table 6 indicates the dilatometry results for the five frits studied. The results in Table 6 show that the frits presented thermal expansion coefficients quite different from the typical values of the ceramic substrates. As a consequence, these frits cannot be applied, on its own, as coating agents, and it is necessary to add other compounds to the frit to increase or decrease the enamel thermal expansion coefficient. In order to investigate if there is a relationship between $\alpha$ and the chemical composition of the frit, we have also calculated, for each frit, the theoretical value of $\alpha$ using the additivity law Eq. (1) [6]. This law admits that each oxide has a different contribution to the final $\alpha$ value. This contribution is described by an oxide characteristic coefficient $\left(\alpha_{i}\right)$ and, thus, $\alpha$ can be estimated by Eq. (1):

$\alpha=\frac{1}{100} \sum \alpha_{i} p_{i} \times 10^{-7}$

Table 6

Dilatometric parameters for the frits studied

\begin{tabular}{|c|c|c|c|c|}
\hline \multirow[t]{2}{*}{ Sample } & \multicolumn{4}{|c|}{ Dilatometric parameter } \\
\hline & $\alpha \times 10^{7}\left({ }^{\circ} \mathrm{C}^{-1}\right)^{\mathrm{a}}$ & $\alpha \times 10^{7}\left({ }^{\circ} \mathrm{C}^{-1}\right)^{\mathrm{b}}$ & $T_{\mathrm{d}}\left({ }^{\circ} \mathrm{C}\right)$ & $T_{\mathrm{s}}\left({ }^{\circ} \mathrm{C}\right)$ \\
\hline A & 72.1 & 85.6 & - & 1125.2 \\
\hline B & 29.8 & 74.7 & - & - \\
\hline $\mathrm{C}$ & 55.7 & 77.9 & 549.5 & 926.5 \\
\hline D & 55.4 & 81.1 & 736.4 & 1122.8 \\
\hline $\mathrm{E}$ & 142.3 & 122.3 & 500.4 & - \\
\hline
\end{tabular}

where $\alpha_{i}$ is the coefficient of oxide $i\left({ }^{\circ} \mathrm{C}^{-1}\right)$ and $p_{i}$ is the wt. $\%$ of oxide $i$ in the sample.

However, for non-homogeneous glasses, as in the case of the glazes or enamels where phase separation or crystallization occurs, the values of $\alpha$ calculated by Eq. (1) may be considerably different from the experimental values [6]. For the frits tested and using the Winkelmann-Schott oxide coefficient values [6], the thermal expansion coefficients determined by Eq. (1) are also given in Table 6 .

It can be noticed that the calculated values in Table 6 show some deviations from the experimental values, as could be expected, since these glasses are not homogeneous (a crystalline phase is present). However, these results allow us to verify some tendencies. The smallest $\alpha$ value is obtained for frit B that has shown two crystallization events, while the highest one is for frit $\mathrm{E}$ that corresponds to a lower degree of crystallization. Therefore, it seems that this correlation can be useful to identify and anticipate the thermal behaviour of a glaze when its composition is manipulated, though it has to be used with caution when dealing with glass-ceramic frits. In fact, in this case, the thermal expansion coefficient is conditioned by the presence and extent of crystallization and may be quite different from the theoretical value.

\subsection{Comparison of the properties of glass-ceramic and traditional frits}

Non-crystalline frits with similar oxide elements as in the glass-ceramic frits studied in this work have also been tested. Table 7 shows the composition of the non-crystalline frits comparable to frit A (frits 1-3). Table 8 shows the thermal properties of those non-crystalline frits, which are compared with frit A properties.

Table 7

Chemical composition of the non-crystalline frits (wt.\%)

\begin{tabular}{lllllllllr}
\hline Frit & $\mathrm{SiO}_{2}$ & $\mathrm{Al}_{2} \mathrm{O}_{3}$ & $\mathrm{Na}_{2} \mathrm{O}$ & $\mathrm{B}_{2} \mathrm{O}_{3}$ & $\mathrm{~K}_{2} \mathrm{O}$ & $\mathrm{CaO}$ & $\mathrm{MgO}$ & $\mathrm{BaO}$ & $\mathrm{ZrO}_{2}$ \\
\hline 1 & 59.0 & 5.0 & 7.0 & 11.0 & 1.0 & 4.0 & 2.0 & 0 & 11.0 \\
2 & 55.0 & 6.0 & 1.0 & 14.0 & 3.0 & 5.0 & 3.0 & 1.0 & 12.0 \\
3 & 57.0 & 8.0 & 2.0 & 9.0 & 4.0 & 8.0 & 3.0 & 0 & 9.0 \\
\hline
\end{tabular}


Table 8

Physical data of both non-crystalline frits and frit A

\begin{tabular}{llllllll}
\hline Frit & \multicolumn{2}{l}{ Dilatometric parameters } & & \multicolumn{3}{l}{ Heating microscopy } \\
\cline { 2 - 5 } \cline { 6 - 8 } \cline { 6 - 8 } & $\alpha \times 10^{7}\left({ }^{\circ} \mathrm{C}^{-1}\right)$ & $T_{\mathrm{d}}\left({ }^{\circ} \mathrm{C}\right)$ & $T_{\mathrm{s}}\left({ }^{\circ} \mathrm{C}\right)$ & & $M\left({ }^{\circ} \mathrm{C}\right)$ & $B\left({ }^{\circ} \mathrm{C}\right)$ & $\mathrm{HB}\left({ }^{\circ} \mathrm{C}\right)$ \\
\hline 1 & 61 & 590 & 665 & & 910 & 1020 & 1085 \\
2 & 65 & 625 & 700 & & 905 & 1025 & 1085 \\
3 & 62 & 645 & 735 & & 990 & 1060 & 1150 \\
$\mathrm{~A}$ & 72 & - & 1125 & & 1247 & - & 1256 \\
\hline
\end{tabular}

In general, it was verified that the values for the thermal expansion coefficients of the traditional frits group were very close to each other, in clear opposition with the discrepancies found on the $\alpha$ values for the glass-ceramic frits. Since the $\alpha$ value of a non-homogeneous glaze depends also on the crystalline phases formed, a relationship between the $\alpha$ values of the glass-ceramics frits and of the traditional frits cannot be established considering only the oxide composition. Concerning the other properties, the dilatometric and heating microscopy temperatures of the crystalline frits are, in general, higher than the temperatures for traditional frits. This fact supports the previous conclusion about the influence of the crystalline phase on the thermal properties of the final product and also that crystalline phase formation, during firing, affects the sintering process.

The composition of the traditional frits studied suggests that crystals can also appear in these frits, namely $\mathrm{ZrSiO}_{4}$ crystals. In order to check this possibility we have conducted DRX analysis for frit 2 (higher $\mathrm{ZrO}_{2}$ content), both with the raw frit and after submitting the frit to heat treatment up to $1050{ }^{\circ} \mathrm{C}$. These results are shown in Figs. 12 and 13, respectively. It is evident that for frit 2 the crystalline phase already existed in the raw frit, its magnitude increasing slightly after heat treatment. Thus, in this case, we cannot speak of a real crystallization process during firing but rather of a growth of the original grains. In fact the $\mathrm{ZrSiO}_{4}$ crystals are usually very small being easily dispersed in the liquid matrix of the frit during processing and acting mainly as opacifying agent, without leading to a substantial increase of the enamel resistance as happens with the crystalline frits. This agrees with the difference in thermal properties between frits 2 and A.

\subsection{Influence of additives on the crystalline structure of frits}

The influence of additives on the crystalline structures formed during firing was studied for frits B and D, using DTA

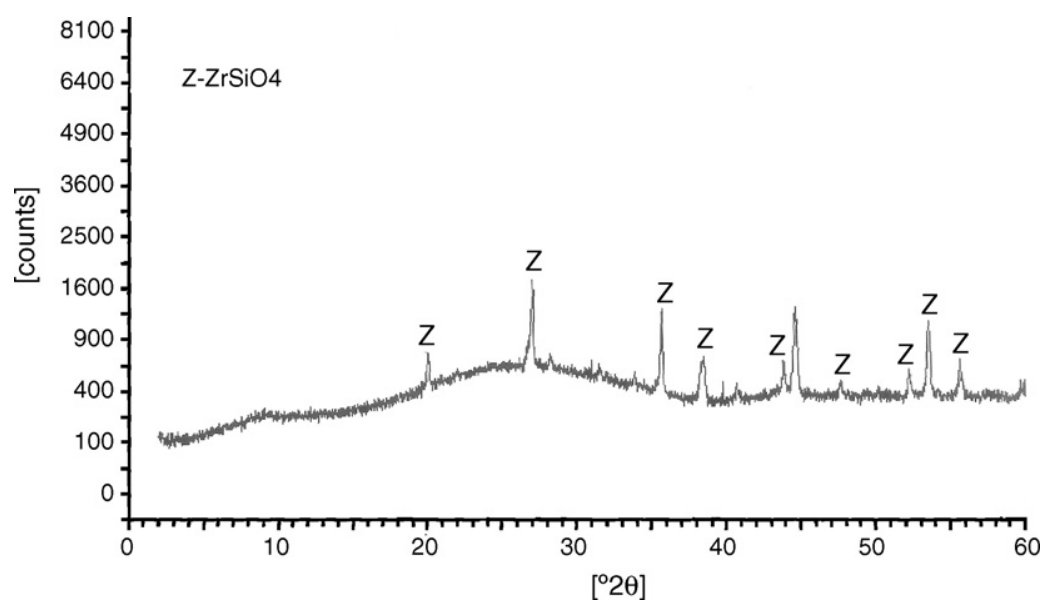

Fig. 12. X-ray pattern of raw frit 2 .

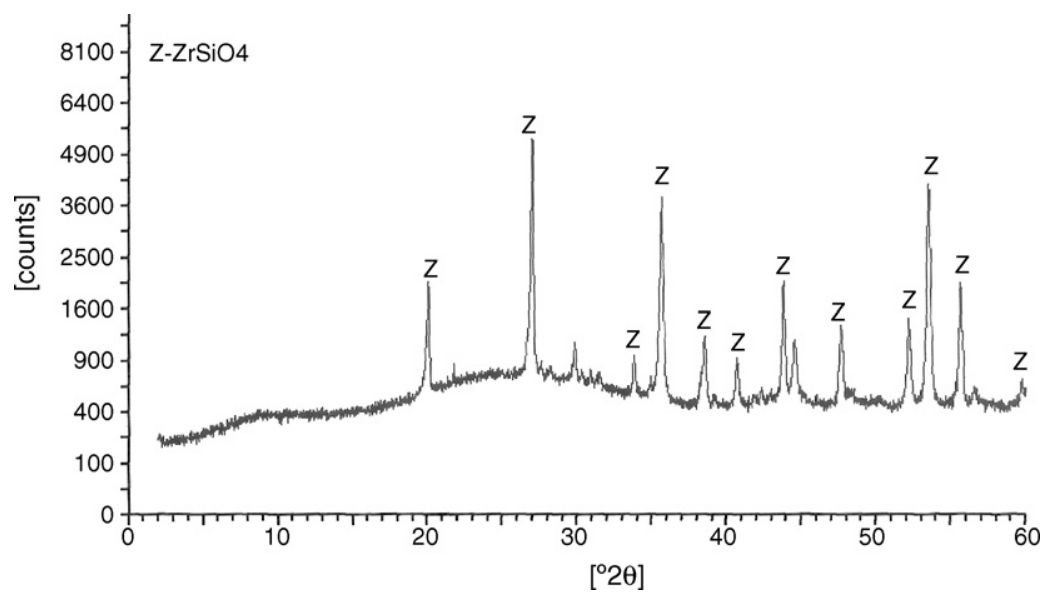

Fig. 13. X-ray pattern of sintered frit 2 at $1050{ }^{\circ} \mathrm{C}$. 


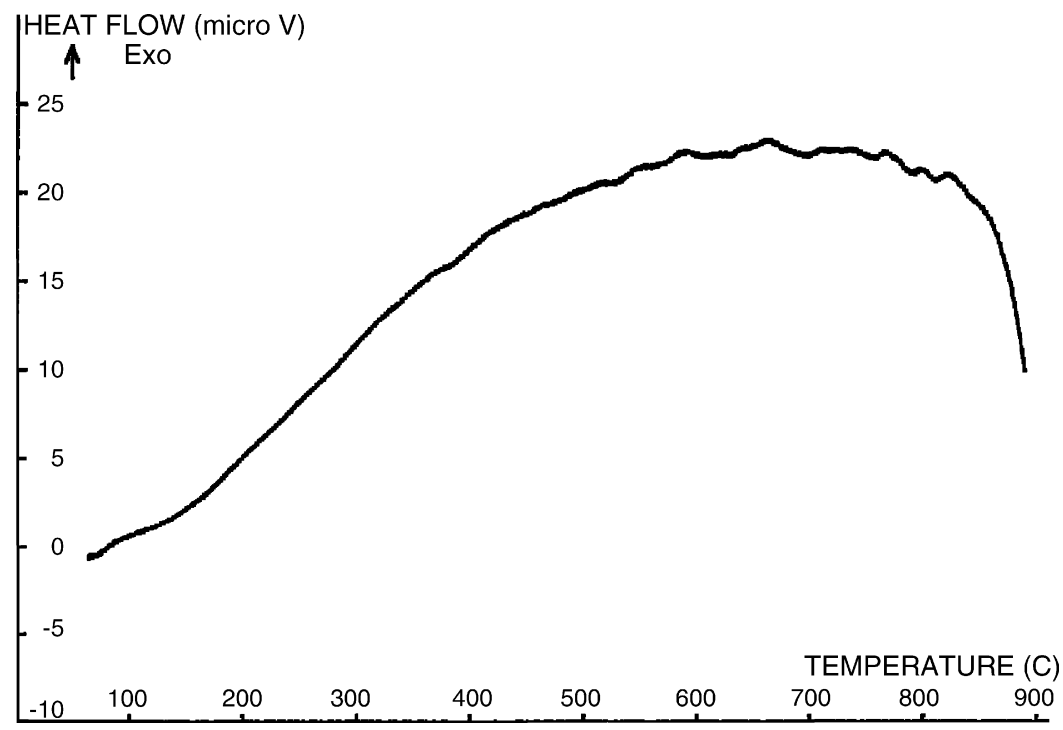

Fig. 14. DTA curve for sample M.

analysis and XRD. In the case of frit $\mathrm{D}, 5 \%$ of alumina was added to the frit to verify if the addition of alumina was effective in promoting the anorthite formation. The new chemical composition of the frit (sample $\mathrm{M}$ in Table 3) shows the same glass-ceramic system, CAS, as the pure frit. However, reporting to the ternary phase diagram [5], the mixture equilibrium point is now located in the anorthite formation area. Thus, anorthite crystallization is expected during firing. Nevertheless, in this case, the alumina particles are distinct from the frit particles and this may limit the crystallization of anorthite. In fact, the distance between the particles is larger in this case than if alumina was part of the frit itself, and reactions can become more difficult. DTA was used to follow the heat treatment of sample M, the result being presented in Fig. 14 .

This diagram is quite similar to the diagram obtained for the isolated frit D. Indeed, the curve does not make evident the occurrence of the exothermic peak characteristic of a devitrification process. However, the heat flow is greater in this case than for sample D. Sample M was also analysed by XRD to determine its structure evolution until $1100{ }^{\circ} \mathrm{C}$. These results are shown in Fig. 15.
Fig. 15 indicates that sample $M$ exhibits a crystalline phase at $1100{ }^{\circ} \mathrm{C}$ whereas the $\mathrm{X}$-ray patterns for the pure frit $\mathrm{D}$ did not display any diffraction peaks. These diffraction peaks are characteristic of the anorthite structure. At 0 and $690{ }^{\circ} \mathrm{C}$ peaks characteristic of alumina have also been detected, as expected. Thus, it is possible to conclude that alumina addition effectively promoted anorthite formation and, in this case, frit D starts behaving like a glass-ceramic frit. It is important to note that the crystalline structure was detected, by XRD, at $1100{ }^{\circ} \mathrm{C}$. However, the maximum temperature applied in the DTA analysis was $900{ }^{\circ} \mathrm{C}$ to avoid crucible damage (the softening point of frit $\mathrm{D}$ is lower than $1100{ }^{\circ} \mathrm{C}$ ). This may explain why the DTA result could not be clearly linked to the XRD pattern, since crystallization started only after the softening point of the isolated frit $\mathrm{D}$, which is higher than the maximum temperature used in the DTA test. This unusual behaviour may be due to the fact that, in sample $M$, frit $D$ particles are distinct from the alumina particles, as referred above, and, thus, softening must occur first before any reactions can start taking place.

It was also studied a composed enamel (sample $\mathrm{N}$ ) containing approximately $37 \%$ of frit $\mathrm{B}$, in order to determine

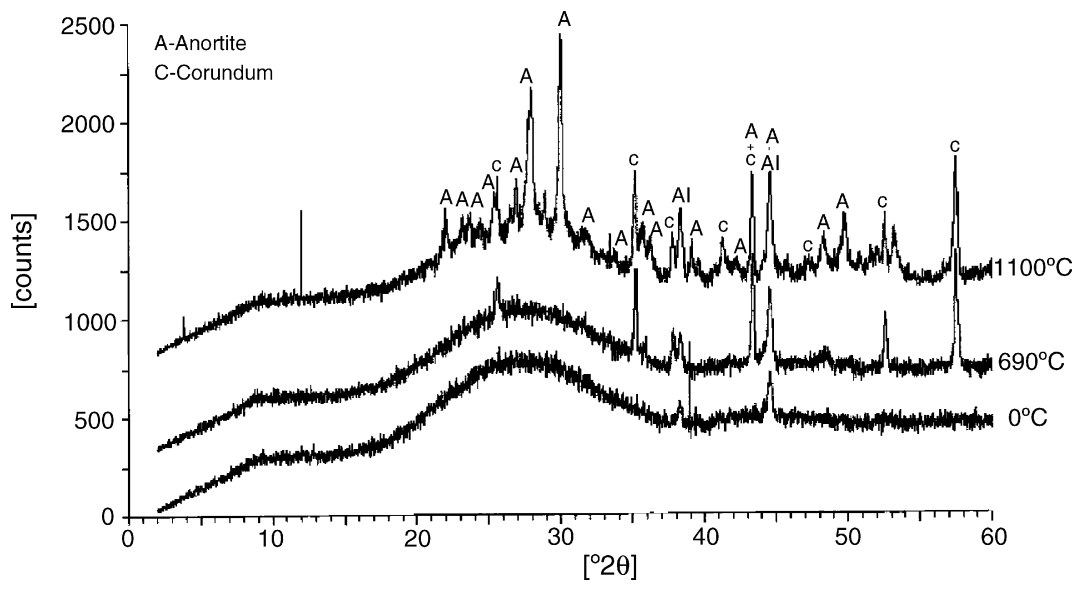

Fig. 15. X-ray diffraction patterns for the sintered sample M. 
the influence of additives on the crystallization process. This enamel is used as a very thin coating film which is spread over a non-crystalline enamel to increase resistance of the final product. The other compounds of the enamel were kaolin, petalite, dolomite and zirconium silicate. Sample $\mathrm{N}$ had a complex composition (see Table 3) thus it was difficult to foresee the crystalline structure of the sintered samples through the phase diagram alone. We have carried out DTA and XRD analyses to try to assess the firing process of this sample.

Until $720{ }^{\circ} \mathrm{C}$ sample $\mathrm{N}$ loses mass due to the carbonated compounds content. At $953{ }^{\circ} \mathrm{C}$ there is an exothermic peak with small amplitude. After that, at $1100{ }^{\circ} \mathrm{C}$, cordierite and indialite have been identified. Comparing the results for this enamel with the frit B results presented previously (Figs. 9 and 11), both samples devitrificated leading to the formation of cordierite and indialite at similar temperatures. So, additives did not influence the crystal formation temperature. However, in the case of the composed enamel, we could not demonstrate that the cordierite and indialite formation implied the formation of an intermediate compound $\left(\mathrm{MgAl}_{2} \mathrm{Si}_{3} \mathrm{O}_{10}\right)$ as happened with frit $\mathrm{B}$ alone. In addition, both the enamel and frit $\mathrm{B}$ devitrificated leading to the formation of a lithium phase, though forming compounds with different structure. The petalite added to frit B, enriching the enamel with lithium, was responsible for the changes on the final structure of the lithium phase.

The study of enamel $\mathrm{N}$ has proved that it is possible to add some additives to glass-ceramic frits in order to allow its use as coating of ceramic bodies, without altering significantly the crystallization events. In fact, since the $\alpha$ values of glassceramic frits and ceramic supports can be quite different, it is sometimes necessary to correct the enamel composition in order to obtain compatible $\alpha$ values, assuring, nevertheless, that this correction does not inhibit crystallization. The crystalline frits can be used either as coatings or can be incorporated in the ceramic paste to increase densification and thus resistance of the body. In the first case the frit can either be applied as a thin film that increases resistance of the final product or, on the other hand, it can be used to produce a complete enamel but, in this case, the $\alpha$ value of enamel and body have to be compatible what can be achieved by using adequate additives.

\section{Conclusions}

Chemical analysis allows the identification of the main glass-ceramic systems exhibited during the firing of glassceramic frits. The main crystalline phases resulting from devitrification during firing and the range of temperatures for which these transformations occur, were also identified. It has been shown that all the sintered frits, exception made for frit D, exhibited a significant crystalline structure. The correlation between the devitrification and sintering processes leads to the conclusion that the glass transition temperature occurs always before the sintering point and when crystallization starts the sintering process stops, the softening temperature occurring always after the crystallization process. Thus, the main conclusion is that crystal formation interferes on the sintering process of glass-ceramic frits.
The dilatometry results demonstrated that it is necessary to use additives to obtain a thermal expansion coefficient compatible with the ceramic bodies. Confrontation of theoretical $\alpha$ values, obtained by means of additive law, with experimental values, confirmed that the $\alpha$ value of non-homogeneous glazes depends also on the crystalline phase and not only on oxide composition. Thus, one has to be very cautious when using theoretical calculations to predict the $\alpha$ value of crystalline frits. Comparison between the thermal properties of traditional frits and of glass-ceramic frits shows that the $\alpha$ values of the traditional frits are very similar to each other, in opposition to the very different values found for crystalline frits. Moreover, the dilatometric and heating microscope temperatures of crystalline frits are substantially higher than the temperatures obtained for traditional frits with similar compositions. Thus, the influence of crystal formation, during firing, and of the crystalline phase content of the final product, on the thermal properties of glassceramic frits, has been demonstrated.

The study of additivated frits confirmed that it is possible to induce the formation of a crystalline phase, in a glass-ceramic matrix, by an adequate addition of complementary compounds. In the case of frit $\mathrm{D}$ it is necessary to add alumina for crystalline phase formation to occur. Furthermore, the tests with the composed enamel allowed us to conclude that the additives used to correct the thermal expansion coefficient of the enamels have got limited influence on the main structures (crystalline phases) identified on the sintered product obtained with the isolated frits. They can, nevertheless, affect the structure of minority intermediate phases and, thereafter, lead to the formation of crystals with slightly different structures.

In the future, it will be interesting to evaluate the microstructure of the crystals formed in these products by using scanning electronic microscopy.

\section{Acknowledgements}

We would like to thank the collaboration of Colorobbia Portugal, Lda. in making available the necessary facilities for the development of this work. We are also grateful for the collaboration of Centro Tecnológico da Cerâmica e do Vidro (Coimbra, Portugal) that provided essential equipment to perform this work.

\section{References}

[1] C. Leonelli, T. Manfredini, Vidrados vitrocerâmicos para queima rápida, Cerâm. Ind. 1 (3) (1996) 31-34.

[2] C. Lira, A.P. Novaes de Oliveira, O.E. Alarcon, Sintering and crystallisation of $\mathrm{CaO}-\mathrm{Al}_{2} \mathrm{O}_{3}-\mathrm{SiO}_{2}$ glass powder compacts, Glass Technol. 42 (3) (2001) 91-96.

[3] A.E. Benlloch, Vidrados cerâmicos de natureza vitrocristalina: Parte II, Cerâm. Ind. 6 (3) (2001) 33-43.

[4] J.L. Amorós, Vidrados para pavimentos e revestimentos cerâmicos: Evoluções e perspectivas: Parte I, Cerâm. Ind. 6 (4) (2001) 41-50.

[5] E.M. Levin, H.F. McMurdie, Phase Diagrams for Ceramists, The American Ceramic Society, New York, 1975.

[6] J.L. Amorós, A. Blasco, J.V. Carceller, V. Sanz, Acordo Esmalte-Suporte (II): Expansão Térmica de Suportes e Esmaltes Cerâmicos, Cerâm. Ind. 2 $(1 / 2)(1997) 8-16$. 